\title{
The superexacerbator phenotype in patients with COPD: a descriptive analysis
}

\section{To the Editor:}

Exacerbations are pivotal events in the natural history of chronic obstructive pulmonary disease (COPD), as they contribute to quality-of-life impairment, disease progression, hospitalisations and mortality [1-4]. Therefore, exacerbation prevention is one of the major goals in the management of patients with COPD, although a subgroup of patients with optimal treatment may still experience exacerbations [5].

HURst et al. [6] described the high variability in the incidence of exacerbations, with a subgroup of patients that had persistently frequent exacerbations during 3 years of follow-up. Indeed, the study showed that the best predictor of future exacerbations was having experienced multiple exacerbations in the previous year [6]. Consequently, since the Global Initiative for Chronic Obstructive Lung Disease (GOLD) 2011 document, exacerbation history has been included in the evaluation of severity of COPD. Subjects with two or more exacerbations in the last year are considered at high risk of future events, which influences treatment decisions [5]. However, recently, HaN et al. [7] showed in the Subpopulations and Intermediate Outcome Measures in COPD Study that the most consistent exacerbator phenotype was the inconsistent exacerbator, with only a very small group of subjects that suffered from repeated years of two or more exacerbations. Although this study showed a high individual variability in annual exacerbation frequency, subjects with a history of very frequent (three or more) exacerbations have shown to be better responders to add-on pharmacological interventions that reduce exacerbation risk, such as macrolides and phosphodiesterase type 4 inhibitors [8,9]. In an accompanying editorial, WEDZICHA [10] described this group of patients as "superexacerbators" and emphasised the need to increase our understanding of this complex group of patients at high risk.

In this study, we aimed to evaluate the prevalence of this superexacerbator phenotype, defined as having experienced at least three exacerbations in the previous year, in a sample of subjects entering pulmonary rehabilitation. Moreover, we compared the clinical characteristics of subjects without exacerbations, with one or two exacerbations, or with three or more exacerbations in the previous year, and studied the association between exacerbation frequency and clinical characteristics.

We performed a retrospective study of COPD patients who consecutively completed a 3-day assessment for pulmonary rehabilitation at CIRO (Horn, the Netherlands) between May 2005 and November 2013 [11]. Data were extracted from the CIRO data centre (ethical committee agreement METC 13-4-013). The board of directors of CIRO approved the use of these de-identified data. A physician performed a structured interview, including number of exacerbations and medical history. An exacerbation was defined as a period of worsening of symptoms leading to treatment with antibiotics and/or oral steroids and/or hospitalisation. COPD-Specific Co-Morbidity Test index was calculated [12]. Pearson's chi-squared test was used for categorical or ordinal variables and one-way ANOVA for continuous variables. When appropriate, post hoc least significant difference multiple comparisons were performed. Multiple ordinal analysis was performed with the number of exacerbations in the previous year $(0-1,2-3$ or $\geqslant 4)$ as the dependent variable, and including forced expiratory volume in $1 \mathrm{~s}\left(\mathrm{FEV}_{1}\right)$ as percentage of predicted, residual volume (RV) as percentage of predicted, COPD Assessment Test (CAT) score, modified Medical Research Council (mMRC) questionnaire, 6-min walking distance, fat-free mass index, diffusion capacity, arterial oxygen tension, arterial carbon dioxide tension, sex and (any cause) hospitalisation in the previous

@ERSpublications

The superexacerbator is highly prevalent in patients with COPD entering rehabilitation and these patients have worse disease overall http://bit.ly/30q2k7M

Cite this article as: Vanfleteren LEGW, Boonen LMC, Spruit MA, et al. The superexacerbator phenotype in patients with COPD: a descriptive analysis. ERJ Open Res 2019; 5: 00235-2018 [https:// doi.org/10.1183/23120541.00235-2018]. 
year in the model. These variables were chosen based on the significant differences between the exacerbation frequency groups. To avoid collinearity, only one measure of spirometry (FEV $1 \%$ predicted) and one measure of static lung volumes (RV \% predicted) were chosen to include in the model. All analyses were performed using SPSS Statistics 24 for Windows (IBM Corp., Armonk, NY, USA). A p-value $\leqslant 0.05$ was considered statistically significant.

Data from 1549 COPD patients were available from the data centre, of whom 1349 (87\%) patients met the inclusion criteria. Patients had mild to very severe COPD and a high disease burden, with a mean CAT score of $>20$ points and $85 \%$ of subjects having a mMRC score of $\geqslant 2$ points. Of these patients, $20 \%$ had no exacerbations in the previous year, $35 \%$ had one or two exacerbations, and $45 \%$ had three or more exacerbations (table 1).

Patients in the different exacerbation frequency strata were comparable in age, current smoking status and pack-years, BMI, and COTE index. Patients with three or more exacerbations were more frequently female,

TABLE 1 Characteristics of study patients and different strata of exacerbation frequency

\begin{tabular}{|c|c|c|c|c|c|c|c|c|c|}
\hline Variables & $\begin{array}{l}\text { Patients } \\
\mathbf{n}\end{array}$ & $\begin{array}{c}\text { All } \\
\text { patients }\end{array}$ & $\begin{array}{l}\text { Patients } \\
\mathrm{n}\end{array}$ & $\begin{array}{c}\text { Patients } \\
\text { with no } \\
\text { exacerbations }\end{array}$ & $\begin{array}{l}\text { Patients } \\
\mathbf{n}\end{array}$ & $\begin{array}{l}\text { Patients with } \\
\text { one or two } \\
\text { exacerbations }\end{array}$ & $\begin{array}{c}\text { Patients } \\
\mathbf{n}\end{array}$ & $\begin{array}{l}\text { Patients with } \\
\text { three or more } \\
\text { exacerbations }\end{array}$ & p-value \\
\hline Age years & 1349 & $65.3 \pm 8.7$ & 267 & $66.0 \pm 9.2$ & 478 & $65.4 \pm 8.6$ & 604 & $64.9 \pm 8.6$ & 0.227 \\
\hline Males & 1349 & $682(50.6 \%)$ & 267 & $165(61.8 \%)$ & 478 & $235(49.2 \%)$ & 604 & $282(46.7 \%)$ & $<0.001^{\#}$ \\
\hline Current smokers & 1272 & $311(24.4 \%)$ & 253 & $59(23.3 \%)$ & 450 & $116(25.8 \%)$ & 569 & $136(23.9 \%)$ & 0.706 \\
\hline $\begin{array}{l}\text { Smoking history } \\
\text { pack-years }\end{array}$ & 1349 & $41.0 \pm 19.0$ & 267 & $41.7 \pm 19.1$ & 478 & $40.3 \pm 18.5$ & 604 & $41.2 \pm 19.3$ & 0.582 \\
\hline Chronic oxygen therapy & 1326 & $305(23.0 \%)$ & 263 & $32(12.2 \%)$ & 471 & $111(23.6 \%)$ & 592 & $162(27.4 \%)$ & $<0.001^{\#}$ \\
\hline BMI $\mathrm{kg} \cdot \mathrm{m}^{-2}$ & 1331 & $26.4 \pm 5.9$ & 263 & $27.0 \pm 5.9$ & 472 & $26.4 \pm 5.8$ & 596 & $26.2 \pm 6.0$ & 0.180 \\
\hline FFMI $\mathrm{kg} \cdot \mathrm{m}^{-2}$ & 1310 & $16.8 \pm 2.5$ & 262 & $17.4 \pm 2.7$ & 460 & $16.6 \pm 2.3$ & 588 & $16.7 \pm 2.5$ & $<0.001^{\#}$ \\
\hline FEV $1 \%$ predicted & 1349 & $48.0 \pm 20.8$ & 267 & $60.1 \pm 21.6$ & 478 & $47.9 \pm 20.2$ & 604 & $42.9 \pm 18.6$ & $<0.001^{\uparrow}$ \\
\hline FVC $\%$ predicted & 1349 & $94.7 \pm 22.2$ & 267 & $102.6 \pm 21.2$ & 478 & $96.1 \pm 22.2$ & 604 & $90.2 \pm 21.5$ & $<0.001^{\Uparrow}$ \\
\hline FEV $/$ FVC ratio & 1349 & $37.5 \pm 12.9$ & 264 & $44.0 \pm 14.0$ & 478 & $37.1 \pm 12.4$ & 604 & $34.9 \pm 11.9$ & $<0.001^{1}$ \\
\hline ITGV \% predicted & 1292 & $147.3 \pm 39.3$ & 264 & $130.6 \pm 36.1$ & 461 & $148.4 \pm 37.8$ & 567 & $154.2 \pm 39.6$ & $<0.001^{9}$ \\
\hline TLC \% predicted & 1291 & $115.3 \pm 19.5$ & 264 & $109.9 \pm 19.6$ & 461 & $115.8 \pm 19.0$ & 566 & $117.5 \pm 19.5$ & $<0.001^{\#}$ \\
\hline RV \% predicted & 1291 & $160.2 \pm 55.1$ & 264 & $135.0 \pm 45.6$ & 461 & $160.6 \pm 52.9$ & 566 & $171.7 \pm 57.2$ & $<0.001^{\uparrow}$ \\
\hline TLco $\%$ predicted & 1247 & $50.0 \pm 17.3$ & 257 & $55.3 \pm 18.3$ & 451 & $49.5 \pm 16.2$ & 539 & $47.9 \pm 17.3$ & $<0.001^{\#}$ \\
\hline Kco \% predicted & 1247 & $64.9 \pm 22.5$ & 257 & $69.3 \pm 24.1$ & 451 & $63.6 \pm 21.0$ & 539 & $63.9 \pm 22.7$ & $0.002^{\#}$ \\
\hline $\mathrm{PaO}_{2} \mathrm{kPa}$ & 1278 & $9.3 \pm 1.5$ & 261 & $9.6 \pm 1.6$ & 450 & $9.3 \pm 1.5$ & 567 & $9.2 \pm 1.5$ & $0.015^{\#}$ \\
\hline $\mathrm{PaCO}_{2} \mathrm{kPa}$ & 1279 & $5.4 \pm 1.0$ & 261 & $5.1 \pm 0.7$ & 450 & $5.5 \pm 0.9$ & 568 & $5.6 \pm 1.1$ & $<0.001^{\#}$ \\
\hline COTE index & 1289 & & 264 & & 454 & & 571 & & 0.733 \\
\hline$<4$ & & $\begin{array}{c}1162 \\
(90.1 \%)\end{array}$ & & $238(90.2 \%)$ & & $413(91.0 \%)$ & & $511(89.5 \%)$ & \\
\hline$\geqslant 4$ & & $127(9.9 \%)$ & & $26(9.8 \%)$ & & $41(9.0 \%)$ & & $60(10.5 \%)$ & \\
\hline CAT score & 1270 & $22.0 \pm 6.4$ & 252 & $19.3 \pm 6.6$ & 458 & $21.5 \pm 6.4$ & 560 & $23.7 \pm 5.8$ & $<0.001^{\pi}$ \\
\hline 6MWD m & 1326 & $399.0 \pm 119.1$ & 266 & $450.5 \pm 105.2$ & 471 & $404.6 \pm 110.5$ & 589 & $371.3 \pm 123.3$ & $<0.001^{\Uparrow}$ \\
\hline 6MWD \% predicted & 1317 & $63.5 \pm 17.8$ & 262 & $64.4 \pm 17.9$ & 467 & $64.9 \pm 17.2$ & 588 & $62.1 \pm 18.2$ & $0.023^{+}$ \\
\hline mMRC dyspnoea score & 1341 & & 266 & & 475 & & 600 & & $<0.001^{1}$ \\
\hline 0 & & $18(1.3 \%)$ & & $6(2.3 \%)$ & & $7(1.5 \%)$ & & $5(0.8 \%)$ & \\
\hline 1 & & $184(13.7 \%)$ & & $69(25.9 \%)$ & & $64(13.5 \%)$ & & $51(8.5 \%)$ & \\
\hline 2 & & $557(41.5 \%)$ & & $131(49.2 \%)$ & & $215(45.3 \%)$ & & $211(5.2 \%)$ & \\
\hline 3 & & $326(24.3 \%)$ & & $38(14.3 \%)$ & & $118(24.8 \%)$ & & $170(8.3 \%)$ & \\
\hline 4 & & $256(19.1 \%)$ & & $22(8.3 \%)$ & & $71(14.9 \%)$ & & $163(27.2 \%)$ & \\
\hline $\begin{array}{l}\text { Hospitalisations in last } \\
\text { year }\end{array}$ & 1344 & & 267 & & 476 & & 601 & & $<0.001^{\uparrow}$ \\
\hline 0 & & $721(53.6 \%)$ & & $254(95.1 \%)$ & & $288(60.5 \%)$ & & $179(9.8 \%)$ & \\
\hline 1 & & $321(23.9 \%)$ & & $12(4.5 \%)$ & & $143(30.0 \%)$ & & $166(7.6 \%)$ & \\
\hline 2 & & $146(10.9 \%)$ & & $1(0.4 \%)$ & & $41(8.6 \%)$ & & $104(7.3 \%)$ & \\
\hline 3 & & $62(4.6 \%)$ & & $0(0.0 \%)$ & & $0(0.0 \%)$ & & $62(10.3 \%)$ & \\
\hline$\geqslant 4$ & & $94(7.0 \%)$ & & $0(0.0 \%)$ & & $4(0.8 \%)$ & & 90 (15.0\%) & \\
\hline Intensive care in last year & 1339 & $108(8.1 \%)$ & 266 & $7(2.6 \%)$ & 476 & $39(8.2 \%)$ & 597 & $62(10.4 \%)$ & $0.001^{\#}$ \\
\hline \multicolumn{10}{|c|}{ 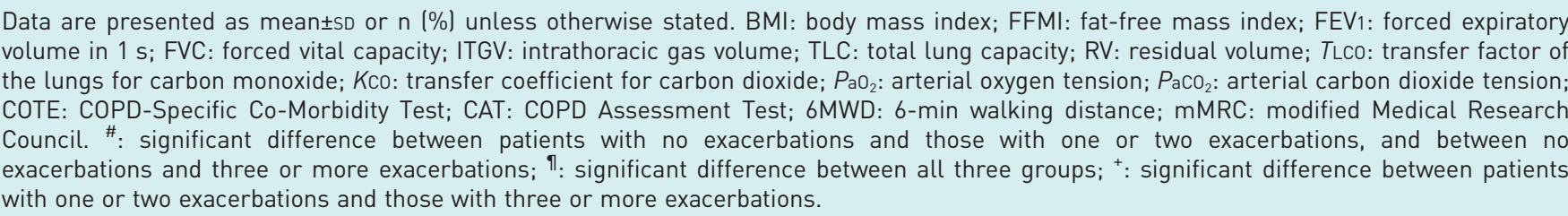 } \\
\hline
\end{tabular}


more often used long-term oxygen therapy, had slightly lower BMI and fat-free mass index, had worse airflow obstruction, had more static hyperinflation, had lower diffusion capacity, had worse blood gasses and had worse exercise capacity compared to subjects with fewer exacerbations (0 or 1-2). While $72 \%$ of subjects without exacerbations in the previous year had mMRC score $\geqslant 2$ points, this was $91 \%$ in those with three or more exacerbations. $70 \%$ of patients with three or more exacerbations in the year prior to inclusion had at least one all-cause hospitalisation in that same year, compared to $5 \%$ in those not experiencing exacerbations. Similarly, the amount of all-cause intensive care hospitalisations was higher in those patients in the higher exacerbation groups. In multiple ordinal analysis, FEV1 \% predicted, RV \% predicted, CAT score and the amount of previous (all cause) hospitalisations in the previous year were independently associated with a higher number of exacerbations. It is of note that these variables could together only explain $38.8 \%$ of the outcome variance.

This study showed that the superexacerbator phenotype, defined as three or more exacerbations in the previous year, is highly prevalent in a large, real-life cohort of patients with moderate to severe COPD entering pulmonary rehabilitation. Indeed, almost half of patients suffered at least three exacerbations in the previous year, while only one in five had no exacerbations. These superexacerbators had worse disease overall, with more pronounced airflow limitation and static hyperinflation, more impaired exercise capacity, and a higher degree of symptoms.

Worse airflow limitation has been repeatedly shown to be a key determinant of exacerbation risk, although high variability within each GOLD stage of airflow obstruction has been demonstrated [6]. We also observed a broad range in FEV1 $(9.4-152.4 \%$ predicted) in the superexacerbator group, which also occurred in the subgroup of patients with one or two exacerbations. Importantly, independently from FEV1 \% predicted, RV \% predicted was associated with more frequent exacerbations. Although the role of hyperinflation in exacerbation risk is broadly acknowledged [13], this is, to our knowledge, the first report that demonstrates that this association is independent of the degree of airflow limitation.

Interestingly, in this cohort, the superexacerbator phenotype was more associated with female sex, but this was not independent from other variables [14].

Although a slightly lower body weight was noted, no differences in the COTE index, a COPD-specific, comorbidity-based prognostic index, was seen [12].

In $70 \%$ of patients with three or more exacerbations, there was at least one all-cause hospitalisation, but presumably in the majority of cases related to COPD. Even $25 \%$ had three or more hospitalisations and $10 \%$ had at least one intensive care stay. This emphasises the tremendous disease burden of these patients as well as the huge impact of these patients on the healthcare system [3].

The strength of this study is the large, real-life, well-characterised cohort of subjects in secondary and tertiary care. Limitations are the inherent retrospective character of the cohort, and the interview-based assessment of the history of exacerbations, although this is how the GOLD strategy recommends addressing future exacerbation risk [5]. Secondly, given the high variability over time of exacerbation frequency, a longer period of evaluation would have been desirable to study the stability of this phenotype and select those patients with a stable superexacerbator phenotype. Third, our study population is not representative of the global COPD population, as the patients are already in need of pulmonary rehabilitation. Finally, severity of the exacerbations cannot be assessed in our data.

In conclusion, the superexacerbator phenotype is frequent in a cohort of subjects entering pulmonary rehabilitation, and is clinically relevant based on its general worse disease status and high healthcare utilisation.

Lowie E.G.W. Vanfleteren $\oplus^{1,2}$, Lotte M.C. Boonen ${ }^{1}$, Martijn A. Spruit $\oplus^{1,3,4}$, Daisy J.A. Janssen ${ }^{1}$, Emiel F.M. Wouters ${ }^{1,3}$ and Frits M.E. Franssen $\oplus^{1,3}$

${ }^{1}$ CIRO, Horn, The Netherlands. ${ }^{2}$ COPD Center, Institute of Medicine, Sahlgrenska University Hospital, University of Gothenburg, Gothenburg, Sweden. ${ }^{3}$ Dept of Respiratory Medicine, Maastricht University Medical Centre (MUMC+), Maastricht, The Netherlands. ${ }^{4}$ NUTRIM School of Nutrition and Translational Research in Metabolism, Maastricht, The Netherlands.

Correspondence: Lowie E.G.W. Vanfleteren, COPD Center, Vita Stråket 12, Sahlgrenska University Hospital, Institute of Medicine, University of Gothenburg, 41345 Gothenburg, Sweden. Email: lowie.vanfleteren@gu.se

Received: Dec 052018 | Accepted after revision: April 262019

Author contributions: L.M.C. Boonen, F.M.E. Franssen, E.F.M. Wouters and L.E.G.W. Vanfleteren conceived and designed the study. L.M.C. Boonen, M.A. Spruit, F.M.E. Franssen, E.F.M. Wouters and L.E.G.W. Vanfleteren drafted the 
manuscript. L.M.C. Boonen and L.E.G.W. Vanfleteren acquired and analysed the data. L.M.C. Boonen and L.E.G.W. Vanfleteren analysed and interpreted the data. L.M.C. Boonen, M.A. Spruit, F.M.E. Franssen, E.F.M. Wouters and L.E.G.W Vanfleteren drafted the manuscript for important intellectual content. All co-authors critically revised the article and gave final approval of this version to be published.

Conflict of interest: L.E.G.W. Vanfleteren reports personal fees from AstraZeneca, Chiesi, Pulmonx, GlaxoSmithKline and Novartis, outside the submitted work. L.M.C. Boonen has nothing to disclose. M.A. Spruit has nothing to disclose in relation to the submitted work. D.J.A. Janssen has nothing to disclose in relation to the submitted manuscript. E.F.M. Wouters has nothing to disclose in relation to the submitted manuscript. F.M.E. Franssen has nothing to disclose in relation to the submitted work.

\section{References}

1 Mullerova H, Maselli DJ, Locantore N, et al. Hospitalized exacerbations of COPD: risk factors and outcomes in the ECLIPSE cohort. Chest 2015; 147: 999-1007.

2 Donaldson GC, Law M, Kowlessar B, et al. Impact of prolonged exacerbation recovery in chronic obstructive pulmonary disease. Am J Respir Crit Care Med 2015; 192: 943-950.

3 Molinari N, Chanez $\mathrm{P}$, Roche $\mathrm{N}$, et al. Rising total costs and mortality rates associated with admissions due to COPD exacerbations. Respir Res 2016; 17: 149.

4 Miravitlles M, Ferrer M, Pont A, et al. Effect of exacerbations on quality of life in patients with chronic obstructive pulmonary disease: a 2 year follow up study. Thorax 2004; 59: 387-395.

5 Vogelmeier CF, Criner GJ, Martinez FJ, et al. Global Strategy for the Diagnosis, Management, and Prevention of Chronic Obstructive Lung Disease 2017 Report: GOLD Executive Summary. Eur Respir J 2017; 49: 1700214.

6 Hurst JR, Vestbo J, Anzueto A, et al. Susceptibility to exacerbation in chronic obstructive pulmonary disease. N Engl J Med 2010; 363: 1128-1138.

7 Han MK, Quibrera PM, Carretta EE, et al. Frequency of exacerbations in patients with chronic obstructive pulmonary disease: an analysis of the SPIROMICS cohort. Lancet Respir Med 2017; 5: 619-626.

8 Uzun S, Djamin RS, Kluytmans JA, et al. Azithromycin maintenance treatment in patients with frequent exacerbations of chronic obstructive pulmonary disease (COLUMBUS): a randomised, double-blind, placebo-controlled trial. Lancet Respir Med 2014; 2: 361-368.

9 Martinez FJ, Rabe KF, Sethi S, et al. Effect of roflumilast and inhaled corticosteroid/long-acting $\beta 2$-agonist on chronic obstructive pulmonary disease exacerbations ( $\left.\mathrm{RE}^{2} \mathrm{SPOND}\right)$. A randomized clinical trial. Am J Respir Crit Care Med 2016; 194: 559-567.

10 Wedzicha JA. Oral phosphodiesterase-4 inhibitors for chronic obstructive pulmonary disease "super exacerbators". Am J Respir Crit Care Med 2016; 194: 527-528.

11 Spruit MA, Vanderhoven-Augustin I, Janssen PP, et al. Integration of pulmonary rehabilitation in COPD. Lancet 2008; 371: 12-13.

12 Divo M, Cote C, de Torres JP, et al. Comorbidities and risk of mortality in patients with chronic obstructive pulmonary disease. Am J Respir Crit Care Med 2012; 186: 155-161.

13 Beeh KM, Burgel PR, Franssen FME, et al. How do dual long-acting bronchodilators prevent exacerbations of chronic obstructive pulmonary disease? Am J Respir Crit Care Med 2017; 196: 139-149.

14 Vanfleteren LE, Spruit MA, Groenen M, et al. Clusters of comorbidities based on validated objective measurements and systemic inflammation in patients with chronic obstructive pulmonary disease. Am J Respir Crit Care Med 2013; 187: 728-735. 